\title{
Ocular Delivery of Atenolol Loaded Microsponge in-situ Gel: Development, Characterization and in-vitro Evaluation
}

\author{
Archana Dhyani ${ }^{1, *}$, Ganesh Kumar ${ }^{2}$ \\ ${ }^{1}$ School of Pharmacy, Graphic Era Hill University, Dehradun, Uttarakhand, INDIA. \\ ${ }^{2}$ College of Pharmacy, Shiwalik Campus, Dehardun, Uttarakhand, INDIA
}

\begin{abstract}
Aim/Background: The purpose of the study was to fabricate and evaluate atenolol loaded micro-sponge in-situ gel. Materials and Methods: Oil in Oil Emulsion Solvent Diffusion Technique was used for formulation of microsponges by using different levels of polymers such as Eudragit RS-100 and Ethyl Cellulose. The prepared micro-sponges were evaluated for optical microscopy, percentage yield, drug content, entrapment efficiency and surface morphology studies. The micro sponges were loaded into in-situ gel. The gel was characterized for $\mathrm{pH}$, rheological behavior, in vitro gelling capacity and in vitro drug release study. Results: The smicrosponges were found in the size range of 7.43 to $9.26 \mu \mathrm{m}$. The formulation F1 has smallest particle size while F9 has largest size. The product yield varies from $66.98 \%$ to $89.87 \%$. The drug content was found to be maximum for formulation F8 which is $94.19 \%$. Similarly, the entrapment efficiency was found maximum for formulation F8 which is $93.89 \%$. The gel was characterized for $\mathrm{pH}$. The $\mathrm{pH}$ of drug loaded microsponge gel were found in range of $7.43 \pm 0.27$ to $9.26 \pm 0.61$. Similarly, viscosity ranges from 32 to $39 \mathrm{cps}$. The data of in-vitro release shows that $60.12 \%$ drug was released up to $24 \mathrm{hr}$. Conclusion: The mirosponges laden in situ gel was effectively prepared by oil in oil emulsion solvent diffusion method $10 / 0$ ESDM). Further, the formulation will provide benefits in terms of sustained/controlled release, reduces dosing frequency and provides better compliance to the patient.

Key words: Microsponge, Atenolol, Ethyl Cellulose, Eudragit RS-100, in situ gel.
\end{abstract}

\section{INTRODUCTION}

Eye is one of the complicated sense organ of the human body which is responsible for vision. It has specified anatomy and physiology. ${ }^{1}$ The major troubles in ophthalmic drug delivery is the rapid removal of liquid drop from the eye which ultimately leads to precorneal loss. ${ }^{2}$ Due to removal the precorneal half-life of drugs applied by pharmaceutical formulations is measured to be between 1-3 min. As a result, only the slight amount of about $1-3 \%$ of the dosage really penetrates throughout the cornea and is capable to get into intraocular tissues. Different methods are used for enhancing the bioavailability of drugs. In the past few years many researchers focus on the carriers like nanoparticles and micro particles for targeting the eye. ${ }^{3}$

Microsponge Delivery System (MDS) is spongy, polymeric microspheres, which has the ability to entrap variety of the actives and can control their release. ${ }^{4}$ The mirosponges have size range between 5 to $300 \mu \mathrm{m} .{ }^{5}$ The methods used for fabrication of microsponges includes polymerization, emulsion and solvent diffusion methods. The main advantages of microsponges is that they can be used for a longer time without preservatives because of its pore size. Because of the porous size, the microsponges has high entrapment efficiency and high drug loading. ${ }^{6}$ In situ ocular gels consists polymers
Submission Date: 17-04-2021; Revision Date: 28-07-2021; Accepted Date: 23-12-2021

DOI: 10.5530/ijper.56.1s.45 Correspondence: Ms. Archana Dhyani Assistant Professor, School of Pharmacy Graphic Era Hill University, Dehradun-248001, Uttarakhand, INDIA. E-mail: archana.dhyani89@ gmail.com

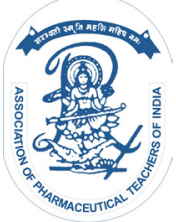

www.ijper.org 
that can changes structurally with changes in $\mathrm{pH}$ and temperature in the environment. These gels are basically in liquid form before installation but after installation it undergoes gelation in the eye and thus slowly releases the medicament. ${ }^{7}$ The advantages of in situ gels involves that they can easily administered, causes reduction in the frequency dosing and increases patient compliance. ${ }^{8}$

Atenolol is a $\beta_{1}$ selective adrenoceptor blocking agent. The topically administered atenolol causes lowering in intraocular pressure. Evidence suggest that reduction in pressure of is due to decreased secretion of aqueous humor.' Many researcher's focused on the various preparations of atenolol. The formulation includes long acting gel of atenolol. ${ }^{10}$ The main demerit of this formulation is that it does not provide sustained or controlled release of medicament. An another formulation isniosomal hydrogel of atenolol. ${ }^{11}$

The aim of the study is integration of microsponges with the in-situ gels. Atenolol loaded microsponges was formulated by using ethyl cellulose and Eudragit RS -100 polymer. Both the polymer are insoluble at ocular $\mathrm{pH}$ and compatible at particular $\mathrm{pH}$. The microsponges is then loaded into in-situ gel which reduces the frequency of dosing of drug and thus helps in better patient compliance.

\section{MATERIALS AND METHODS}

\section{Materials}

Atenolol was obtained from Mepromax Ltd., Dehradun (Uttarakhand). Ethyl cellulose (EC) polymer, acetone, magnesium stearate and light liquid paraffin was obtained from Central Drug House Limited, New Delhi. Eudragit RS-100 was purchased from Evonik India Ltd.

\section{Methods}

\section{Preparation of Atenolol loaded microsponges}

The method used for fabrication of microsponges was O/O ESDM. The polymers such as ethyl cellulose and Eudragit RS-100 was dissolved in acetone. Atenolol was added with magnesium stearate $(5 \% \mathrm{w} / \mathrm{v})$. The mixture was kept for $5 \mathrm{~min}$ for sonication at $3000 \mathrm{rpm}$ (sonics).The mixture was incorporated into $200 \mathrm{ml}$ of light liquid paraffin at $4000 \mathrm{rpm}$ for $3 \mathrm{hr}$. The acetone was completely removed during this period. The microsponge were washed with n-hexane, the dried for a period of $12 \mathrm{hr}$ at room temperature and finally stored in desiccators. ${ }^{12}$

\section{Design of experiment}

Nine formulations (F1-F9) were fabricated by using two different polymers at three different levels. The design is
Table 1: Formulation chart of Atenolol loaded micro sponges using Ethyl Cellulose and Eudragit RS-100.

\begin{tabular}{|c|c|c|c|c|c|c|}
\hline 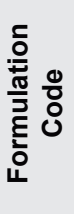 & 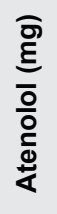 & 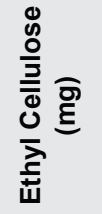 & 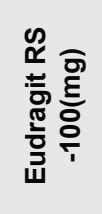 & 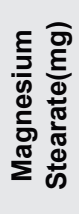 & 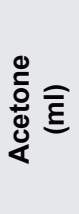 & 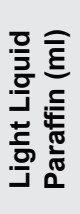 \\
\hline F1 & 90 & $-1(90)$ & $-1(90)$ & 5 & 10 & 200 \\
\hline F2 & 90 & $-1(90)$ & $0(180)$ & 5 & 10 & 200 \\
\hline F3 & 90 & $-1(90)$ & $1(270)$ & 5 & 10 & 200 \\
\hline F4 & 90 & $0(180)$ & $-1(90)$ & 5 & 10 & 200 \\
\hline F5 & 90 & $0(180)$ & $0(180)$ & 5 & 10 & 200 \\
\hline F6 & 90 & $0(180)$ & $1(270)$ & 5 & 10 & 200 \\
\hline F7 & 90 & $1(270)$ & $-1(90)$ & 5 & 10 & 200 \\
\hline F8 & 90 & $1(270)$ & $0(180)$ & 5 & 10 & 200 \\
\hline F9 & 90 & $1(270)$ & $1(270)$ & 5 & 10 & 200 \\
\hline
\end{tabular}

elaborated in Table 1. The amount of atenolol of drug and magnesium stearate was maintained at constant value.

\section{Evaluation of Microsponges}

\section{Particle size by optical microscopy}

Optical microscopy was used for particle size analysis. 100 particles were measured and the mean particle was determined. ${ }^{13}$

\section{Product yield}

The product yield was determined by using formula: ${ }^{14}$

$$
\text { Product yield }=\frac{\text { Total microsponges formed }}{\text { Total amount of drug and excipients }}
$$

Total amount of drug and excipients

\section{Drug content (DC)and entrapment efficiency(EE)}

$50 \mathrm{mg}$ drug loaded microsponges were weighed and dissolved in $5 \mathrm{ml}$ acetone. The sample was place in centrifuge for $10 \mathrm{~min}$ at $4500 \mathrm{rpm}$. The supernatant layer was collected assayed at $274 \mathrm{~nm}$. The \% DC and EE efficiency was calculated. ${ }^{4}$

\section{Microsponges surface morphology}

Field Emission scanning electron microscopy (FESEM) was used to determine the morphology of microsponges. ${ }^{15}$

\section{Development of Atenolol loaded microsponges in situ gels}

The calculated amount of Poloxamer $407(30 \% \mathrm{w} / \mathrm{v})$ was introduced to distilled water by mixing. The mixture was exposed at $4^{\circ} \mathrm{Cin}$ a refrigerator for overnight until the whole polymer swells. Once a clear viscous solution is formed, the weighed quantity of microsponges was 
introduced to the solution. The solution formed was put under sonication for $1 \mathrm{~min}$ to form a gel. ${ }^{16}$

\section{Evaluation of microspongeloaded gel pH determination}

The $\mathrm{pH}$ of was determined with the help of of $\mathrm{pH}$ meter. The average reading was recorded. ${ }^{17}$

\section{Rheological behavior determination}

The rheology of prepared gels was determined using viscosity. The viscosity was determined at $50 \mathrm{rpm}$ by using Brookfield Viscometer. The readings were taken in triplicates. ${ }^{18}$

\section{In -vitro gelling capacity}

The method for determination of in-vitro gelling capacity involves the use of fresh drop of gel in vial which contains $2 \mathrm{ml} \mathrm{PBS} \mathrm{pH} 7.4$ at $37^{\circ} \mathrm{C}$. The time duration for gelation was noted down. The different grades were given according to gelling capacity. ${ }^{18}$

\section{In vitro release study of atenolol loaded microsponges in-situ gel formulations}

In-vitro release test was carried out in $50 \mathrm{ml}$ of PBS $(\mathrm{pH} 7.4)$ in Franz Diffusion cell. A semi permeable membrane (Himedia) was used for the study. An accurate weight of $0.5 \mathrm{~g}$ of microsponge gel was put on the cell. The samples were withdrawn from the cell at regular time period (1 to $24 \mathrm{hr}$ ) and were analyzed at $274 \mathrm{~nm}$ in spectrophotometer. Kinetic analysis was done to determine the order of reaction. The release data was put into kinetic models to find out the mechanism of drug release. ${ }^{19}$

\section{Stability Study}

In stability studies the microsponge gel were stored at $40^{\circ} \mathrm{C}$ and $75 \% \mathrm{RH}$ for a period of three months. The two parameters mean particle size and entrapment efficiency were evaluated.

\section{RESULTS AND DISCUSSION}

The microsponges were prepared by O/O ESDM. Acetone served as a good solvent and bridging liquid for atenolol. The microsponges were subjected to different evaluation parameters and the results are mentioned in Figure 1 (A,B,C,D) and Table 2

\section{Particle size}

The microsponges varies from $7.43 \pm 0.27$ to $9.97 \pm 0.61 \mu \mathrm{m}$. F9 formulation consist maximum particle size when both ethyl cellulose and Eudragit RS 100 were at maximum level. The particle size should be within the range of $10 \mu \mathrm{m}$. The particle having size below $10 \mu \mathrm{m}$
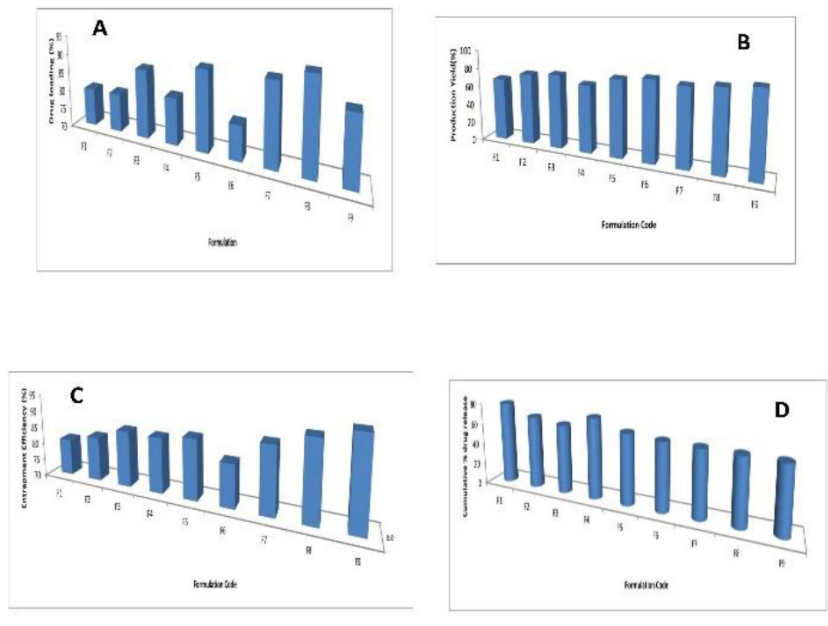

Figure 1: (A)-Percent drug loading of Micropsonges (B) Production Yield of Micropsonges (C)-Entrapment Efficiency of Micropsonges (D)-Cumulative Percent Drug Release of Microsponges.

do not causes irritation to the eyes. The similar type of studies was conducted by Rajasekaran et al 2020 in which they found that the particles below $10 \mu \mathrm{m}$ is suitable and comfortable for ocular delivery. ${ }^{20}$

\section{Product yield}

The yield of the microsponges varies from $66.98 \%$ to $89.87 \%$ as shown in Table 2 . The maximum value was found to $89.87 \%$ for F9 which contain high level of polymers. Furthermore, on raising the level of polymer the product yield increased. Consequently, F1 exhibited low yield of $61.2 \%$ due to low level of polymers.

\section{Drug Content}

The drug content was found maximum for Formulation F8 showed which $93.89 \%$ is. The high percentage of drug content was due to the porous structure of microsponges which favors the maximum drug loading. The high drug loading leads to increased drug content of the formulation.

\section{Percentage Entrapment Efficiency}

The percentage entrapment efficiency usually varies from $80.76 \%$ to $92.89 \%$. It was found maximum for formulation F8 94.19\%.and minimum $80.76 \%$ for F1. The EE can be associated to the porous structure of microsponges. The porous nature of microsponges favors high entrapment efficiency. The DC and \% EE depend on the drug to polymer concentration. Higher value of drug to polymer ration favors high drug content and entrapment efficiency. This is in correlation with the results quoted by Bhatia et al. 2018, Obiedallah et al. $2018 .{ }^{4,7}$ 


\begin{tabular}{|c|c|c|c|c|}
\hline 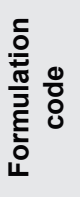 & 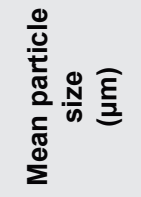 & 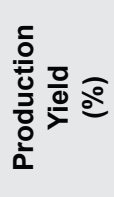 & 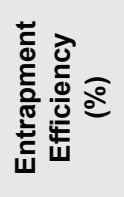 & 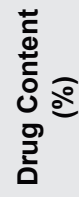 \\
\hline F1 & $7.43 \pm 0.27$ & 66.98 & 80.76 & 79.98 \\
\hline $\mathrm{F} 2$ & $8.89 \pm 0.91$ & 75.92 & 82.89 & 80.12 \\
\hline F3 & $8.68 \pm 0.29$ & 78.98 & 86.25 & 87.99 \\
\hline $\mathrm{F} 4$ & $8.82 \pm 0.36$ & 71.98 & 85.89 & 82.17 \\
\hline F5 & $9.12 \pm 0.49$ & 81.98 & 87.25 & 90.78 \\
\hline F6 & $8.89 \pm 0.28$ & 85.99 & 82.19 & 78.93 \\
\hline F7 & $8.99 \pm 0.99$ & 82.98 & 88.91 & 90.09 \\
\hline F8 & $9.21 \pm 0.76$ & 86.32 & 94.19 & 93.89 \\
\hline F9 & $9.26 \pm 0.61$ & 89.87 & 92.89 & 89.14 \\
\hline
\end{tabular}
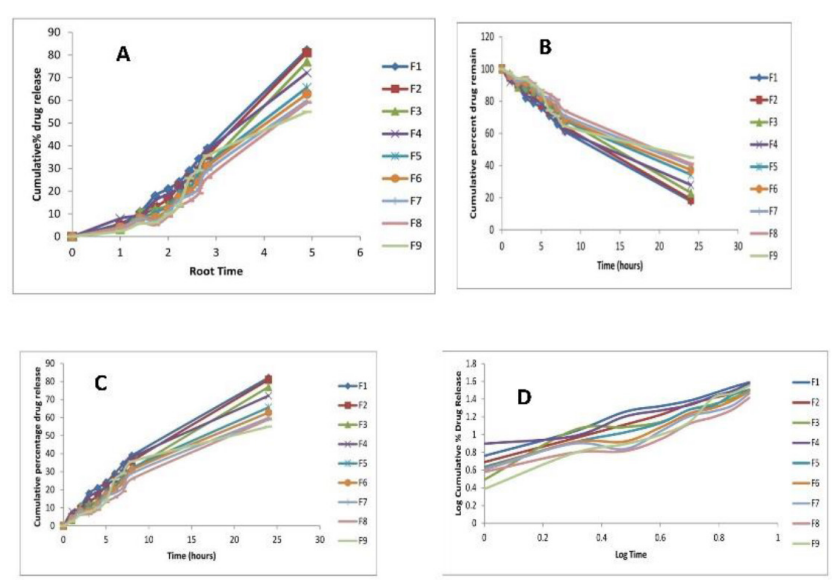

Figure 2: (A) - Zero Order Release Plot (B) - First Order Release Plot (C) - Higuchi's Plot (D) -Korsmeyer's Peppas Plot.

\section{Microsponges surface morphology}

The FESEM of mirosponges shows that they are round in shape with porous surface as shown in Figure 3. The same results was obtained by Tripathi et al. 2019. In their study they prepared the microsponges of dithranol. The formed microsponges were found uniform and spherical in shape. In another study, the same type of results were also obtained by Obiedallah et al. 2018. ${ }^{4}$ in which the FESEM of micropsonges shows that they are spherical and uniform in size.

\section{Evaluation of Gel loaded Microsponges}

The different parameters were evaluated for gel loaded microsponges which includes $\mathrm{pH}$, viscosity, gelling capacity and gelling time determination and stability studies. The results of gel loaded microsponges are shown in Table 3.

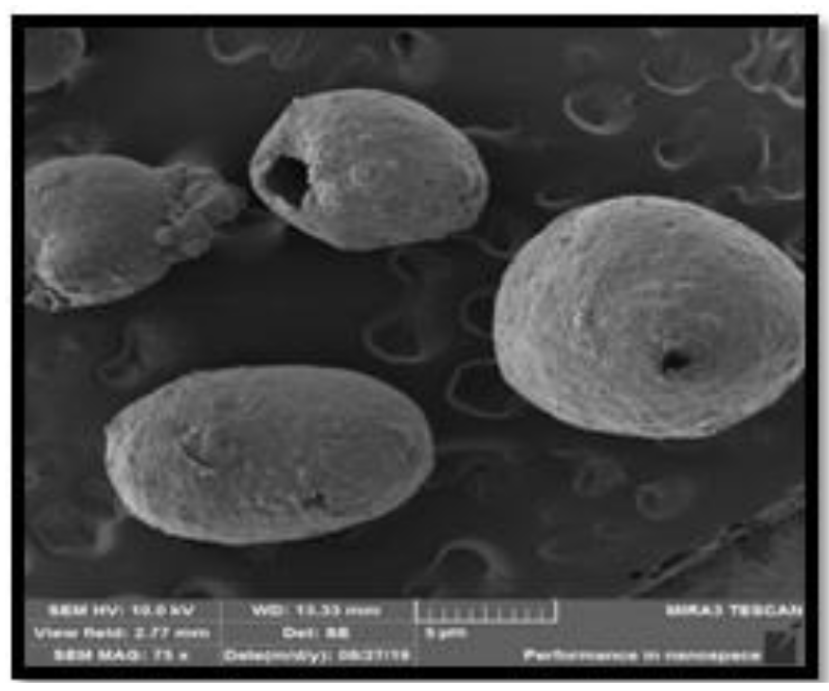

Figure 3: Scanning Electron Microscopy of formulation F8.

$\mathrm{pH}$

The ideal value of $\mathrm{pH}$ for an ophthalmic product is 7.4. The $\mathrm{pH}$ of different formulation was found in the range of 6-7 which shows that the formulation is suitable for ocular delivery. Any change in $\mathrm{pH}$ could leads to ocular irritation. So, the $\mathrm{pH}$ of the formulation should lie within the specified range. The work done by Makwana et al. 2016 in which they found the $\mathrm{pH}$ of their formulation between 6.49-6.58 which is suitable for ocular delivery. ${ }^{21}$

\section{Rheological behavior}

The viscosity was determined with the help of Brookfield viscometer. The viscosity helps to enhance the residence time of formulation in the targeted organ eye. The viscosity of the gel was found in between 32-39 cps. The ocular formulation must have adequate viscosity so that it remain inside the eye. This value of viscosity is suitable for the ocular delivery.

\section{Gelling capacity and gelling time}

The ideal in-situ system is the one which gelled on exposure to body temperature. The minimum gelling time was found to be $9.89 \pm 0.73 \mathrm{sec}$ for F1 formulation. The gelling time is low for the formulation having low entrapment efficiency $(80.76 \%)$. The results finds correlation with the Obiedallah et al. 2018. ${ }^{4}$

\section{In vitro Release of Atenolol Loaded Microsponges in situ Gel Formulations}

The in-vitro release study of microsponges loaded in situ gel was conducted in Franz Diffusion cell. The release data was calculated for all the formulations and the results are shown in Table 4. From the study, it was found that the formulation F9 has slowest rate of drug release 


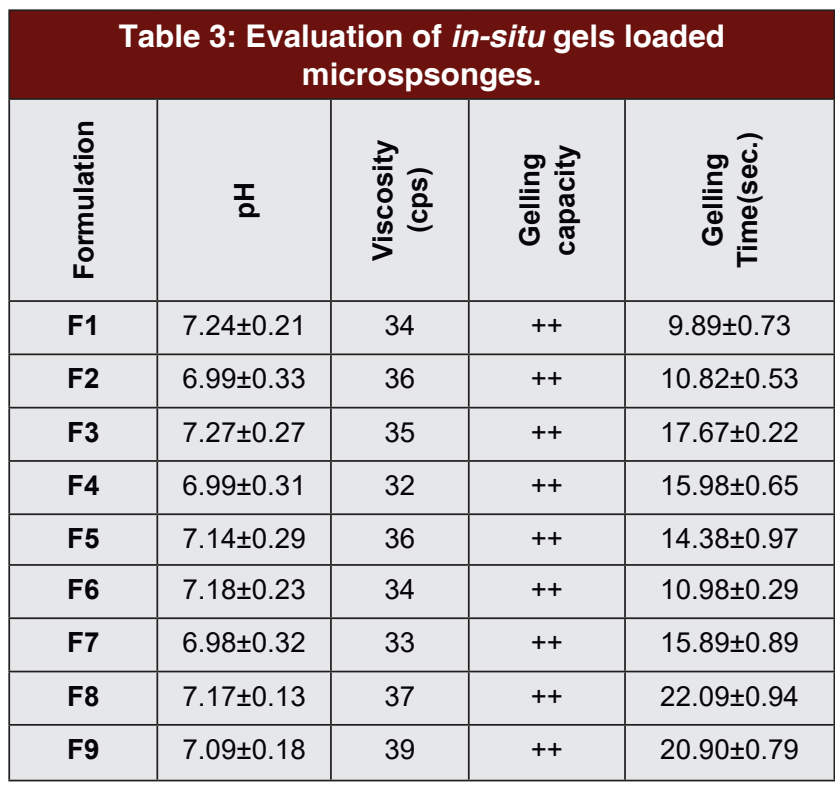

\begin{tabular}{|c|c|c|c|c|c|}
\hline 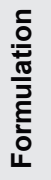 & 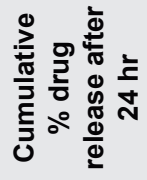 & 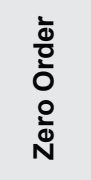 & 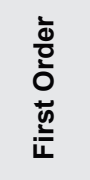 & 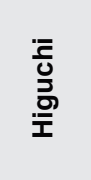 & 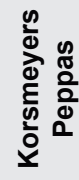 \\
\hline $\mathrm{F} 1$ & 79.32 & 0.969 & 0.970 & 0.954 & 0.993 \\
\hline F2 & 68.90 & 0.985 & 0.989 & 0.928 & 0.997 \\
\hline F3 & 64.89 & 0.991 & 0.991 & 0.910 & 0.945 \\
\hline F4 & 75.45 & 0.956 & 0.956 & 0.955 & 0.961 \\
\hline F5 & 65.66 & 0.966 & 0.968 & 0.926 & 0.986 \\
\hline F6 & 62.78 & 0.969 & 0.97 & 0.924 & 0.961 \\
\hline F7 & 61.81 & 0.972 & 0.975 & 0.913 & 0.927 \\
\hline F8 & 60.88 & 0.982 & 0.985 & 0.886 & 0.929 \\
\hline F9 & 60.12 & 0.854 & 0.855 & 0.884 & 0.962 \\
\hline
\end{tabular}

due to high concentration of polymer. The release data was put under different mathematical models to find out the release mechanism. The data is subjected to kinetic models like zero order, first order, Higuchi's, Korsmeyer Peppas as shown in Figure 2 When the data is plotted between time vs drug release the best fit model was found to be first order as it shows high range of linearity. The value of $R^{2}$ is less than 0.9 for all formulations. The value of $n$ is found to be greater than 0.89 which shows that case II transport mechanism.

\section{Stability studies}

The stability studies of the prepared microsponges were conducted and the results are shown in Table 5. From the studies it was found that there were no changes occurs in entrapment efficiency and mean particle size of formulations during the storage period.

\begin{tabular}{|c|c|c|}
\hline \multicolumn{3}{|c|}{ Table 5: Stability study of formulation after three } \\
months. \\
\hline $\begin{array}{c}\text { Formulation } \\
\text { code }\end{array}$ & $\begin{array}{c}\text { Mean Particle } \\
\text { Size( } \boldsymbol{\mu m})\end{array}$ & $\begin{array}{c}\text { Encapsulation } \\
\text { Efficiency } \\
(\%)\end{array}$ \\
\hline F1 & $7.76 \pm 0.45$ & 80.75 \\
\hline F2 & $8.92 \pm 0.93$ & 81.78 \\
\hline F3 & $8.64 \pm 0.71$ & 86.11 \\
\hline F4 & $8.62 \pm 0.37$ & 85.9 \\
\hline F5 & $9.32 \pm 0.49$ & 86.98 \\
\hline F6 & $8.99 \pm 0.28$ & 82.10 \\
\hline F7 & $8.89 \pm 0.99$ & 88.76 \\
\hline F8 & $9.21 \pm 0.76$ & 93.98 \\
\hline F9 & $9.55 \pm 0.61$ & 92.76 \\
\hline
\end{tabular}

\section{CONCLUSION}

Atenolol loaded microsponge in situ gel was successfully prepared by oil in oil solvent emulsion diffusion method. The microsponge loaded in-situ gel was subjected to different evaluation parameters. From the results, it was found that the microsponges was successfully prepared and having spherical in shape. The size of the microspsonges was found upto $10 \mu \mathrm{m}$ which is suitable for ocular delivery. The most optimized formulation was found to be F8 due to its satisfactory results of particle size, drug content, entrapment efficiency, $\mathrm{pH}$, viscosity. At the last, it was concluded that the formulation will have in reducing frequency of dosing, provides sustained action and improves the patient compliance.

\section{ACKNOWLEDGEMENT}

The authors are thankful to Graphic Era Hill University, Dehradun for providing equipment and facilities.

\section{CONFLICT OF INTEREST}

The authors declare that there is no conflict of interest.

\section{ABBREVIATIONS}

Rpm: Revolutions per minute; $\mu \mathrm{m}$ : Micrometer; Cps: Centripoise; PBS: Phosphate buffer saline. O/O ESDM: Oil in oil emulsion solvent diffusion method; \%: Percentage; DC: Drug content; EE: Entrapment efficiency.

\section{REFERENCES}

1. Barar J, Aghanejad A, Fathi M, Omidi Y. Advanced drug delivery and targeting technologies for the ocular diseases. BiolMPacts. 2016;6(1):49-67. doi: 10.15171/bi.2016.07, PMID 27340624. 
2. Andreas Z, Kreuter J. Microspheres and nanoparticles used in ocular delivery systems. Adv D Del Rev. 1995;16(3):61-73.

3. Hong YZ, Ji LH, Shuang W. Nanoparticles in the ocular drug delivery. Int J Ophthal. 2003;6(3):390-6.

4. Obiedallah MM, Abdel-Mageed AM, Elfaham TH. Ocular administration of acetazolamide microsponges in situ gel formulations. Saudi Pharm J. 2018;26(7):909-20. doi: 10.1016/j.jsps.2018.01.005, PMID 30416345.

5. Nokhodchi A, Jelvehgari M, Siahi MR, Mozafari MR. Factors affecting the morphology of benzoyl peroxide microsponges. Micron. 2007;38(8):834-40. doi: 10.1016/j.micron.2007.06.012, PMID 17692528.

6. Mahant S, Kumar S, Nanda S, Rao R. Microsponges for dermatological applications: perspectives and challenges. Asian J Pharm Sci. 2020;15(3):273-91. doi: 10.1016/j.ajps.2019.05.004, PMID 32636947.

7. Ruel-Gariépy ER, Leroux JC. In situ-forming hydrogels-review of temperature-sensitive systems. Eur J Pharm Biopharm. 2004;58(2):409-26. doi: 10.1016/j.ejpb.2004.03.019.

8. Nallakantam A. In-situ gel drug delivery system. Int J Pharm Wave. 2015;1(1):73-84.

9. Macdonald MJ, Cullen PM, Phillips $\mathrm{Cl}$. Atenolol versus propranolol. A comparison of ocular hypotensive effect of an oral dose. British Journal of Ophthalmology. 1976;60(11):789-91. doi: 10.1136/bjo.60.11.789.

10. Hassan MA. A long acting ophthalmic gel Formulations of atenolol. Drug Dev Ind Pharm. 2007;33(11):1192-8. doi: 10.1080/03639040701377433, PMID 18058315.

11. Abu Hashim IIA, El-dahan MS, Yusif RM, Abd-EIGawad AE, Arima H. Potential use of niosomal hydrogel as an ocular delivery system for atenolol. Biol Pharm Bull. 2014;37(4):541-51. doi: 10.1248/bpb.b13-00724, PMID 24694602.

12. Sareen R, Nath K, Jain N, Dhar KL. Curcumin Loaded Microsponges for Colon Targeting in inflammatory bowel Disease: fabrication, Optimization and in vitroand Pharmacodynamic Evaluation. BioMed Res Int. 2014;5:1-7.
13. Martin A, Bustamante P, Chun A. Micromeritics in physical pharmacyphysical chemical principles in the Pharmaceutical Science. Vol. 5. Waverly Pvt. Ltd.; 2002. p. 446-8.

14. Oriani VB, Alvim ID, Consoli L, Molina G, Pastore GM, Hubinger MD. Solid lipid Microparticles Produced by Spray Chilling Technique To Deliver Ginger Oleoresin: structure and compound retention. Food Res Int. 2016;80:41-9. doi: 10.1016/j.foodres.2015.12.015.

15. Moin A, Deb TK, Osmani RA M, Bhosale RR, Hani U. Fabrication, characterization, and evaluation of microsponge delivery system for facilitated fungal therapy. J Basic Clin Pharm. 2016;7(2):39-48. doi: 10.4103/09760105.177705, PMID 27057125.

16. Kurniawansyah IS, Rusdiana T, Sopyan I, Ramoko H, Wahab HA, Subarnas A. In situ ophthalmic gel forming systems of poloxamer 407 and hydroxypropyl methyl cellulose mixtures for sustained ocular delivery of chloramphenicole: optimization study by factorial design. Heliyon. 2020;6(11):e05365. doi: 10.1016/j.heliyon.2020.e05365, PMID 33251348.

17. Bhatia M, Saini M. Formulation and Evaluation of curcumin Microsponges for Oral and Topical Drug Delivery. Prog Biomater. 2018;7(3):239-48. doi: 10.1007/s40204-018-0099-9, PMID 30242738.

18. Zhang JQ, Liu J, Li XL, Jasti BR. Preparation and characterization of solid lipid nanoparticles containing silibinin. Drug Deliv. 2007;14(6):381-7. doi: 10.1080/10717540701203034, PMID 17701527.

19. Song J, Bi H, Xie X, Guo J, Wang X, Liu D Preparation and evaluation of sinomenine hydrochloride in situ gel for uveitis treatment. International Immunopharmacology. 2013;17(1):99-107. doi: 10.1016/j.intimp.2013.05.020.

20. Rajasekaran A, Kumaran K, Preetha JP, Karthika KA. Comparative review on conventional and advanced ocular drug delivery formulations. Int J Pharm Tech Res. 2010;2:668-74.

21. Makwana SB, Patel VA, Parmar SJ. Development and characterization of in-situ gel for ophthalmic formulation containing ciprofloxacin hydrochloride. Results Pharma Sci. 2016;6:1-6. doi: 10.1016/j.rinphs.2015.06.001, PMID 26949596.

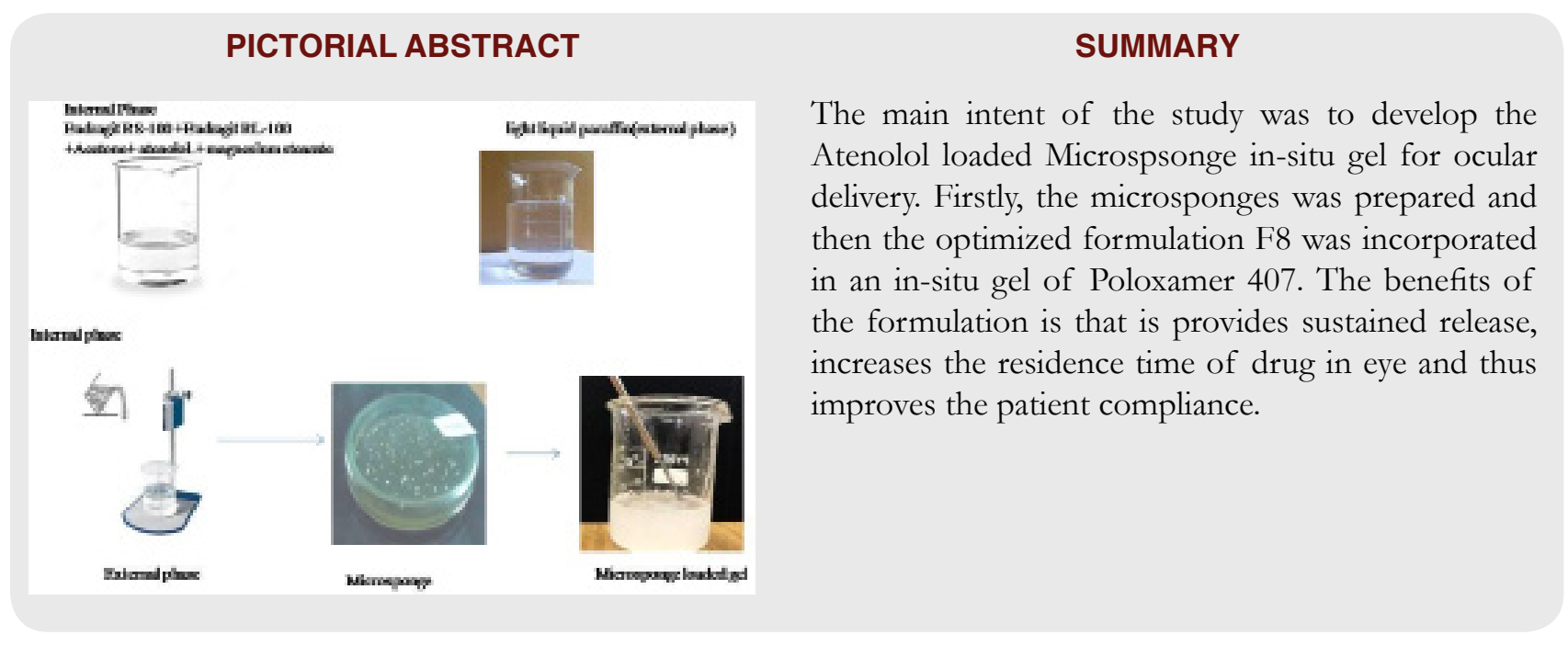

Cite this article: Dhyani A, Kumar G. Ocular Delivery of Atenolol Loaded Microsponge in-situ Gel: Development, Characterization and in-vitro Evaluation. Indian J of Pharmaceutical Education and Research. 2022;56(1s):s75-s80. 